\title{
Effects of the Albanian Forestry Project on Poverty Reduction
}

\author{
Prof.Assoc. Dudi Suli \\ MSc. Nevin Alija \\ MSc. Hergys Suli
}

Agricultural University of Tirana, Faculty of Economics and Agribusiness,

Kodër Kamëz, Tirana, Albania

\section{Doi:10.5901/mjss.2013.v4n9p668}

\begin{abstract}
Finding ways to reduce poverty is a priority of the governments of Albania and in close collaboration with international donors, a concerted effort is being made to focus on those areas that experience a high incidence of poverty, namely the remote rural areas. These areas also coincide largely with the $50 \%$ of Albanian land area that is covered by forests and pastures and it is no coincidence that the government has, with the financial assistance of the World Bank and Governments of Italy and Switzerland, and with the technical Assistance of FAO, implemented a comprehensive forestry project that among other objectives also has poverty reduction as one of its expected outcomes. The collaboration of the World Food Program through its provision of food packages to the forestry workers has been the most direct benefit for the poor. The Albania Forestry Project has funded a range of activities to strengthen the overall forest and pasture administration, improve forest management practices, support the transfer of forests and pastures to the communes and to improve the management of Albania's protected areas. These activities are still ongoing and after completion of the Forestry Project at the end of 2003, important progress towards better resource management and positive economic prospects for many communes will hopefully have been achieved.
\end{abstract}

\section{Introduction}

In 1995, the Albania Government, the WB, the Italian Government and the Swiss Government signed the project documents of the Albania Forestry Project ( FP ). Implementation of the Project commenced in 1996 and after a one-year extension that has just been formalized, the FP is now scheduled to conclude at the end of 2003.

Poverty reduction is one of overriding objectives of the FP that in the course of its six years of activities has involved a wide spectrum of the country's population. Qualitative assessments indicate that the project as a whole has had a positive impact on poverty alleviation and that particularly the CFPM component with its targeted interventions in rural areas, has contributed significantly to reducing poverty in very vulnerable areas. An earlier study of the communal component alone showed that in some areas, employment in forest sector is the only source of local employment, thus reducing poverty and migration. To determine the extent to which the FP has been successful in reducing poverty has been the objective of this study that was carried out as recommended by the FP Joint Supervision Mission of December 2001. The Ministry of Agriculture and Food MOAF has supported the study and has recommended that the results of this study be presented at a national conference. The findings of the study are intended to serve the Government and donors in the design of other projects that have poverty reduction as an objective. The FP, FAO-TA, WFP and SNV have provided financial and technical support for this assessment. Poverty in Albania has received a lot of attention from the Government and also most Donors in the country. The National Strategy for Socio-economic Development issues by the Albanian Council of Ministers identifies poverty as a multi-discplinary phenomenon reflected by the following five indicators:

- Low or very low level of income of the poor

- Higher disease rate and lack of appropriate medical services

- Illiteracy or low level of schooling

- High exposure rate towards risks

- Low voice in government decision making

Based on these defined national indicators, this study has been designed solely to assess the impact of the FP on 
poverty reduction as related to these five indicators. The study analyses historic data from the FP such as disbursement and investment figures and relevant activity records for districts and communes. Furthermore, the study is based on the analysis of original field surveys that has been specifically designed for surveying six distinct target groups, each involved in FP activities at various levels and capacities through Albania. Because this assessment has a narrow focus on FP investments and activities, it is no way a conclusive study on poverty reduction in Albania. However, the results of this assessment provide not only useful information about the performance of the FP but may also may serve as source of information for the assessment of other projects that deal with poverty reduction. More importantly, the findings of this assessment can hopefully help in the design of future assistance activities aimed at poverty reduction.

\section{Methodology for the impact Assessing}

\subsection{Study Concept}

A WG consisting of representatives of the DGFP, PMU, FAO, WFP, SNV and the Agricultural University of Tirana has been created to guide all activities related to this impact assessment. The DGFP was the lead agency for this WG and the FAO-TA coordinated the activities.

\subsection{Survey Analysis}

\subsubsection{Target Groups for survey}

The working group identified six target groups: forestry departments, forestry associations, private contractors, local government, forestry workers and households (directly profiting from the FP and other households) in the area.

\subsubsection{Survey tool}

Two semi-structured questionnaires were created: one targeting organizations and institutions (forestry departments, forest and pasture users associations, private contractors, local government ) and the second one for household representatives ( forestry workers, families helped with food rations and other non-profiting household members.). Each of the two questionnaires included blocks of questions or variables addressing the criteria of the poverty as identified by the government of Albania. The main blocks were:

Level of income

Health, health care and nutrition

Education

Risk factors

Participation on decision-making

\subsubsection{Study Design and sampling strategy}

\section{a) Survey based on institutions/organizations}

The part of the survey based on organizations and institutions ( first four target groups ) was simple and required only the multistage sampling procedure according to the district and communes selected for the household survey ( see below ). A total of thirteen districts were interviewed and one representative from each selected commune (20) resulting in a sample size of approximately on third of the organizations. Selection of the person representing the organization and the selection of the organizations were based on random numbers.

\section{b) The household survey}

As mentioned above the two population-based target groups required a different, more elaborated methodology, in terms of sampling and size, as their target population exceeds one hundred thousand individuals. As the area to be studied was too vast and a total list of households was not available, the cluster survey was selected as the most appropriate design. The multistage procedure was performed previously to randomly select a number of communes where the sample was limited. In order to produce the sampling frame and to ensure the correct randomization, a list of all communes engaged in FP activities was prepared. 
For the multistage sampling a table of random numbers was used.

The selection of the households within one cluster was carried out in the field, as part of data selection of households within the village were required to prevent bias by the interviewers. The different target groups implied that a sample of people not involved in the project was also evaluated in addition to the participants who directly profit form the FP. Consequently two samples where needed irrespectively of their size.

c) Sample sizes

The sample size for the participants in the FP was estimated with specified absolute precision based in the following parameters

Anticipated population proportion (estimated prevalence of the phenomenon) $\mathrm{P}=50 \%$ ( this is the "safest" choice for the population proportion since the sample size required is largest when $\mathrm{P}=0.5$ ) Confidence level $90 \%$.

For the second sample (non-participants in the project ) a more extreme anticipated proportion was chosen $\mathrm{P}=90 \%$ (a less conservative indicator);

Anticipated population proportion $90 \%$

Confidence level $\quad 90 \%$

Absolute precision required $\quad 0.1$

\subsubsection{Training and organization}

Four teams of two or three trained interviewers covered all the sampled areas. A full day training session was held to explain the survey tools and to assure consistency among the interviewers. A detailed map of Albania produced by GIS, helped during the field work, for the localization of the communes.

\subsubsection{Analysis}

For the computer analysis of the data, two databases were set up in EPI Info 6.4 package. The analysis will also be available in a common database format (Microsoft Excel compatible) for future analyses or reference. The outcome and results of the data analysis together with the disbursement data formed the input for elaborating the study report. A comparison is made with the overall poverty situation of Albania, the FP and the results of the analysis. Based on this recommendations and conclusions are drafted.

\section{Results and Discutions}

No other sector has such a fundamental impact on Albania's poverty stricken rural population as the forest and pasture sector. More than half of the country's surface is classified as forests (102600 ha) and pastures (446000 ha), and it is these rural areas where poverty is the most extreme. In Albania, poverty reduce the nations poverty. Thus project impact assessments are of great importance for the government and for donors to find out how well project objectives are being achieved. It is with this perspective that the effects of the Albania Forestry Project (FP) on Poverty Reduction have been assessed.

All state forest and pasture area are administered and managed by the Directorate General of Forest and Pastures. The Albania FP funded by the World Bank (WB) and by the Italian and Swiss Governments is being implemented with the objectives, among others ,to Achieving a sustainable increase in the productivity of forest and pasture areas and to Empowering local governments. The FP and the FAO Technical Assistance Project ( FAO-TA ), under implementation since 1996, focuses on four main aspects of forest and pasture management: institutional strengthening, sustainable forest management, communal forest and pasture management and protected areas management. In combination, these components are expected to have a direct and positive impact on the productivity of these areas, on the reduction of erosion and protection of the many irrigation schemes spread in rural areas. Project activities are also expected to lead to a more rational use of pastureland and to halt the current degradation process that is most threatening to biodiversity and sustainability of ecosystems. At the same time the project is supporting the government's decentralization efforts and is facilitating the actual transfer of forests and pastures to the communes and the strengthening of capacities at all level of the forestry and pasture sector. Since 2001, the World Food Programme (WEP) has also been supporting the project through food aid to ensure a sufficient level of food security for the workers and to allow for timely implementation of the work plans. 
The financial resources of the FP amount to USD 21.6 million, including the USD 2.57 million of the FAO-TA Project. Current allocations to the four components are : Institutional Reform ( USD 5.718 million), Sustainable Forest Management ( USD 9.790 million ), Communal Forest and Pasture Management ( USD 4.819 million) and Protected Areas Management ( USD 1.270 million ). As of June 31, 2002 some USD 12.900 million have been disbursed under the FP and FAO-TA Project. The WFP has so far contributed USD 0.51 USD million in food aid for the Communal Forest and Pasture Management (CFPM) component.

That all these activities have an impact on poverty reduction has been clearly noticed, but this study is the first concrete attempt to actually quantitatively assess these effects. The study was recommended by the FP Joint Supervision Mission of December 2001, and developed and implemented by a multy agency working group ( WG ) composed of representatives of the DGFP,PMU,FAO-TA, WFP,S NV, the Agriculture University of Tirana and Albania National Institute of Health. The study benefited from the availability of existing surveys and reports on poverty in Albania that served as reference material and as the socio-economic baseline against which the effects of the FP were measured. For ease of comparison, the study used the five poverty indicators that are used by the Government decisionmaking. A field survey was carried out using two different questionnaires for sampling five target groups consisting of households, forest workers, Communal Forest and Pasture User's Association ( CFPUA), local governments and District Forest Service ( DFS ). The EPI Info 6.4 package was used for the analysis of the field data. Using the current poverty situation in Albania as a baseline, the assessment was able to establish that the FP has define positive effects on all of the five indicators in the areas surveyed. The total annual income comprising of all cash and in-kind incomes amounts to 130,000 Lek (USD 928). This amount consists of 53,636 Lek household cash income, 39000 Lek cash income from the FP, the WFP food package valued at 11826 Lek and benefits from the forest and pasture resources valued at 25538 Lek. Thus the total annual income related to the FP amounts to 76364 Lek (USD 545), which represents almost 59\% of the total annual household income.

All households in the areas where FP activities are carried out live under extreme poverty conditions-defined as living on less than USD 1 /day/person. Even after taking into account the contributions of the FP has helped in coping with the hardships they face.

As a result of the FP, there have been attitudinal changes towards health and education, although the quantitative assessment was not possible. The effects of the FP on health and education seem to be a facilitating factor rather than a decisive factor since, at least in health care, only $3 \%$ of the respondents would have done without receiving treatment, in the absence of the FP. The vast majority would have borrowed money to pay for treatment if they would not have had own financial resources. An interesting fact is that about $45 \%$ of families rely on at least some income generated by school-aged children, which may explain some lower school attendance figures in rural areas.

The effects of the FP on reduction of risks and on the increasing involvement and influence in the decision-making processes are easier to assess. The FP has very much contributed to increasing the transparency of the processes and to facilitating communication and common decision-making in forest and pasture resources management. Although there is still a lot of room for improvement, the benefits are evident and acknowledged by individuals and organizations alike.

The beneficiaries sincerely appreciate the benefits of the FP and WFP. A large majority of respondents also realize that such assistance cannot be continued on a long-term basis to address their problems to look into other viable options such as availability of loans and credits so that they could become sustainable as soon as possible.

Economic viability of rural areas does depend to a large extend on the state of natural resources. Improving their generally poor current state requires substantial long-term investments. While most respondents, individuals and organizations alike, expect the conditions in forest and pasture resource management to improve, even after the FP is completed, it should be noted that the optimism of future be provided by the state. At the same time, most respondents consider the availability of sufficient funding from the state budget one of the critical risk factors.

That a lot of investment is needed is well acknowledged by Albanian and international experts and under current economic conditions, the most likely scenario is that major assistance will have to be made from sources outside the government of Albania, if the benefits of the FP are to be continued and exapanded, and if the rural population is to win the fight against poverty.

\subsection{Main Findings}

\subsubsection{Effects on Households}

The main purpose of this study was to determine the effects of the FP on poverty reduction in Albania. The analysis of 
the responses from the numerous households and organizations has provided very valuable information that allows the authors to formulate the following specific findings.

1. Probably the most important finding of this assessment is that the FP has been able to work with the most appropriate target group, namely the extreme poor in the rural areas, mainly, but not exclusively through the communal forest component. Even prior to this analysis, the benefit of the communal component was recognized and resulted in a re-allocation of over USD 2 million for this component during the midterm evaluation of the FP.

2. The median total income of the surveyed households in 2001 was 130,000 Lek (USD 929), including the cash contributions of the FP and in-kind benefits such as food supplements and the benefits from the utilization of forest and pasture resources. With a household size of 5.4 members, all households involved in the FP fall substantially below the threshold of extreme poverty (defined by Government of Albania as USD 1 day I person ). The FP is one of the few opportunities for many of these households to generate some additional income.

3. The level of income from forestry activities for participating households is estimated at about 39,000 Lek ( USD 270 / year ),or $30 \%$ of total income. This is in line with the level of input, which is on average about 3 months. Obviously, this contribution is not sufficient to really change the poverty status, but for the vast majority of respondents the FP has been an important support in dealing with very difficult living conditions characterized by a desperate lack of employment opportunities, which is one reason why $92 \%$ of the households recognize a positive contribution of the FP.

4. However, it is not only the cash contributions from forestry that are considered beneficial. Forests and pastures are clearly of paramount importance for providing a livelihood for the rural population and their dependency on these resources has been confirmed. Most households generate additional benefits directly from the forest and pasture resources of a cash equivalent of about 25540 Lek ( about USD 182 / year ) from grazing, fodder collection and fuel wood. With households whether or not they are members of the local CFPUA.

5. The WFP food assistance to the communes is a critical stimulus for participation in the FP. The which have to be member of the association in order to qualify for the program.

6. The total income ( cash and kind ) of a household amounts to 130000 Lek, of which some 76364 Lek ( $59 \%$ of the total ) are related to FP activities. Of all the expenses incurred in the households, over $50 \%$ is for food which makes it the most important expenditure item. The contribution of WFP is targeting the most direct need and gives households some more room to make expenditures for other needs. Furthermore the people indicated that the income obtained from the FP is mainly used for food, to a less extent for health, transport and education.

7. The total income of over $50 \%$ of the families surveyed contains contributions from work of their children. In 10 $\%$ of the cases, this contribution amounts to $20 \%$ of the total income. This reliance on contribution from children to family income may explain the lower rural school attendance (especially in the 15 -18 age group). Lack of infrastructure (road access, transportation, schools etc. ) is another factor discouraging school attendance. Education is generally free, but sending children from the village to the high school further away involves often transport costs that many households find difficult to meet. The contribution of the FP helped people to meet these additional needs. This is also supported by the fact that people ranked transport expenses with third importance after food and health.

\subsubsection{Effects on Organizations}

The majority of organizations, state or private noticed an overall increase in funding over the last five-year period and for $57 \%$ of the respondents this increase is due to FP activities. The contributions of the FP is especially important for the CFPUA ( almost $100 \%$ of investments come from the FP) and the private companies who received some $80 \%$ of their 2001 revenues from the FP.

\subsubsection{Effects on Natural Resources}

The FP has a direct impact on the environment and on the future potential of the resources. The investments into forestation, thinning and erosion control have added to the forest growing stock, and growing potential in the communes 
and will contribute a future stream of benefits to these communes. The expected future benefits are in form of better grazing opportunities,increased yields of fodder for livestock, sustainability in fuel wood production and higher value of commercial timber.

\section{Conclusions}

From the data collected and analyzed it can be concluded that the FP has had a positive impact on poverty reduction in Albania in those areas where project activities were implemented. This conclusion can be supported in all five poverty indicators, but only in the analysis of the effect on income can there be a clear quantitative result.The average total income of rural households in the project areas amounts to about 130000 Lek.Over $50 \%$ of the households. It makes them very susceptible to risks, as any reduction to their income will affect almost directly their budget available for food. Thus, support to their income (cash or kind) and food supplies are very effective and will diminish their sensitivity towards risks. The benefits obtained through the FP (income, benefits from forests and pastures and food supplies) can therefore be regarded as very positive for people to secure their basic needs and reducing their risks.

Although this contribution is relatively significant, it is not enough to change the poverty status of the affected families, which remain extremely poor. IT is clearly evident however, that the additional cash resources and food supplements are an important contribution that facilitates coping with the serious problems caused by poverty. One such benefit is that the additional resources enable the families to also consider health care and education needs. This confirms that the FP is able to help the neediest segment of the rural population and as is fulfilling its poverty reduction objectives particularly through CFPM component. That the institutional strengthening, sustainable forest management and protected areas management component also support the poverty reduction objective is also event from the survey. The FP has been very supportive in promoting the transfer of state forests and pasture to the communes for management. Through the improvements of management capabilities at the communal levels, local government and the participating households a more effective partnership with the DFS has been formed, which allows active involment and decision-making by all stakeholders. This process, however, is still at an early stage and should increase with further decentralization and with strengthening of capacity at each level to meet the technical, managerial and administrative requirements.

There is a certain optimism among the stakeholders in the forest sector particularly as the terms of future benefits obtainable from the forest and pasture resources. Closer analysis however shows that this optimism rests on the assumption that the government of Albania continues to invest into the sector after the completion of the FP. Indeed, achieving these general expectations, the efforts towards sustainable forest and pasture management have to be continued. Building on current achievements, the government and the donor community have to provide well-targeted financial and technical support to the forest and pasture sector for many years to come.

\section{References}

Effects of the Albanian forestry project on poverty reduction. A study carried under the Albanian Forestry Project: FAO-TA Project GCP/ALB/004/ITA.

Council regulation (EC) No 1698/2005 of 20 September 2005 on support for ruraldevelopment by the European Agricultural Fund for Rural Development (EAFRD). OJ EU L277 (21.10.2005): 1-40.

Dax, T. 2005. The on-going CAP-reform - incentive for a shift towards rural development activities? MPRA Paper No. 750, Munich Personal RePEc Archive, Munich, $27 \mathrm{pp}$.

European Commission, 2005. Annex to the : proposal for a Council Decision onCommunity strategic guidelines for Rural Development update to Impact Assessment Report; Commission staff working document SEC(2005) 914. European Commission, Brussels, 5.7.2005, $27 \mathrm{pp}$.

Strategjia e Zhvillimit Ekonomik dhe Ulja e Varfërisë, SZHES, 2001

Politikat e Eksencionit Bujqësor, MBUMK, 2001

Zhvillimi Rural në Bashkimin Europian, EU, 2003

Agenda 2000 Europiane, EU 1999

Raporti Vjetor 2005, Banka e Shqipërise

"Strategjia Shqipëtare e Zhvillimit Rural:", Frauke Jungbluth (World Bank) and David Lugg (FAO), 2002.

"Raporti Vjetor 2003", Ministria se Bujqesise dhe Ushqimit. 